\title{
«Albert Camus», 21 (Avec un grand carnet critique). Textes réunis et présentés par Raymond Gay-Crosier
}

\section{Emanuele Kanceff}

\section{(2) OpenEdition Journals}

Edizione digitale

URL: https://journals.openedition.org/studifrancesi/46277

DOI: $10.4000 /$ studifrancesi.46277

ISSN: 2421-5856

\section{Editore}

Rosenberg \& Sellier

\section{Edizione cartacea}

Data di pubblicazione: 1 octobre 2007

Paginazione: 476-477

ISSN: 0039-2944

\section{Notizia bibliografica digitale}

Emanuele Kanceff, ««Albert Camus», 21 (Avec un grand carnet critique). Textes réunis et présentés par Raymond Gay-Crosier», Studi Francesi [Online], 152 (LI | II) | 2007, online dal 30 novembre 2015, consultato il 24 novembre 2021. URL: http://journals.openedition.org/studifrancesi/46277 ; DOI: https://doi.org/10.4000/studifrancesi.46277

Questo documento è stato generato automaticamente il 24 novembre 2021.

\section{c) (†) $\odot$}

Studi Francesi è distribuita con Licenza Creative Commons Attribuzione - Non commerciale - Non opere derivate 4.0 Internazionale. 


\title{
«Albert Camus», 21 (Avec un grand carnet critique). Textes réunis et présentés par Raymond Gay-Crosier
}

\author{
Emanuele Kanceff
}

\section{NOTIZIA}

AA. VV., «Albert Camus», 21 (Avec un grand carnet critique). Textes réunis et présentés par Raymond GAY-CROSIER, Caen, Lettres Modernes Minard, 2007 (Coll. "La Revue des Lettres modernes"), pp. 244.

1 Questo numero 21 della nota serie "Albert Camus" diretta da Raymond Gay-Crosier si distingue dalla norma per la presenza di sole due parti di studi (complessivamente quattro saggi), compensata da un grande "carnet critique" che occupa metà del volume.

2 Nella prima parte, "Camus devant l'histoire», si colloca una articolata analisi di Madalina GRIGORE-MURESAN dal titolo La Réflection historique chez Albert Camus, in cui si ragiona sull'attualità dell'opera camusiana in tempi terribili come i nostri, sulla risorsa unica dell'interrogarsi. In tal senso, l'assurdo, il terrore, la rivolta trovano risposta; ma come associare il processo storico all'assurdità? Perché l'azione dell'uomo impegnato nella marcia degli eventi è generatrice di assurdo? L'A. passa in rassegna gli elementi di questo assurdo della storia e della possibile salvezza: una tensione permanente tra storia e valori, tra divenire e spirito. In un'epoca di capovolgimenti, lo spirito s'interroga, si mette alla ricerca dell'ordine, trova nella realizzazione artistica il significato della vita.

3 Nella seconda parte, tra gli "Studi", si leggono i saggi di Hiroshi Mino su Le Premier homme come storia del silenzio, di Sophie BASTIEN sul teatro di Camus in rapporto alla modernità e di Marcelle MAHASELA sui possibili rapporti tra Camus e Don Chisciotte. È a questo punto che il lettore è chiamato a immergersi in un "Grand carnet critique" che è veramente molto esteso e che, con la sua indagine sulla letteratura critica del 
momento, mostra quanto sia panoramico e universale l'interesse che Camus continua a suscitare. Ottima iniziativa dunque, che ci priva di qualche ulteriore riflessione ma ci regala una consapevolezza critica ben più estesa e importante. Questa parte, che non sarebbe possibile analizzare nel dettaglio, è comunque strutturata in tre "capitoli" rispondenti rispettivamente a studi filosofici, studi tematici e generali, studi politici, culturali e storici, studi estetici e infine studi comparatistici: struttura certamente utile per orientare il lettore, anche se si ha la ovvia sensazione che non sempre sia esattamente praticabile e che, in particolare, l'ultima sezione potrebbe essere arricchita. 